\title{
Moderating effect of environmental turbulence on firm's technological innovation capabilities (TIC) and business performance in the automotive industry in Malaysia: A conceptual framework
}

\author{
Faridah binti Taju Rahim ${ }^{1}$ and Yuserrie bin Zainuddin ${ }^{1, *}$ \\ ${ }^{1}$ Faculty of Industrial Management, Universiti Malaysia Pahang, Lebuhraya Tun Razak \\ 26600 Gambang, Kuantan, Pahang, Malaysia
}

\begin{abstract}
The dimensions that constitute the technological innovation capabilities (TIC) can be a source to improve business performance. Based on the resource-based view and contingency theory, this paper tries to propose a conceptual model to further understand the moderating role of environmental turbulence in effecting of the firm's TIC on firm's business performance in the automotive industry in Malaysia. This paper then developed into concrete research hypotheses for future studies. The conceptual model will serve to guide further research in the area, which can be expected to contribute in the development of automotive industry in Malaysia. Empirical testing of this proposed model is expected in future study using survey instrument.
\end{abstract}

\section{Introduction}

There are increasing studies regarding how a firm can maintain their sustainable competitive advantage and improve firm performance in fast changing and unpredictable environments due to the globalization of markets, technological change, shortening product lifecycles and innovative new product development (NPD) [2-4]. One popular approach used to understand competitive dynamics is the resource-based view (RBV) of the firm. According to this view, only those firms who have the unique resources and capabilities provide the ability for competitive advantage in rapidly changing and unpredictable environments then leads to higher performance. If the firms' resources and capabilities are valuable, rare, hard to imitate, cannot be substituted and the firm also could organize and fully utilized those resources and capabilities, then they could lead to better performance [5-8].

Technological innovation capabilities (TIC) has been considered as a significant strategic resource allowing firms to attain sustainable competitive advantage when firms meet a dynamic environment [9-11]. Firms with more TIC can perform better in more

\footnotetext{
*Corresponding author: yusserie@ump.edu.my
} 
turbulent environments as compared with firms with lesser levels of TIC. Since superior TIC can help firms receive greater efficiency gains by pioneering process innovations, and to achieve higher differentiation by innovating products in response to the changing market environment [3,12-14]. Moreover, superior TIC can accelerate the development of new product developments and adopt new processes in shorter lead time in order to reap the pioneer [15-17]. As a result, TIC can help a firm to create more value than its competitors and can receive a greater economic return above the industry average [18]. Facing competitive business environment, firms are required recurring technological innovation to continuously retain their competitiveness and to face new challenges $[11,19,20]$. Therefore, the firms must assimilate firm resources and TIC to maintain and improve their performance. According to Yam, Guan, Pun, \& Tang (2004) in a dynamic environment, an inability to innovate eventually causes businesses to deteriorate and firms to go out of business.

In the context of internal organization, firms tend to suffer from lack of resources, especially tangible asset. However, in external circumstance, a firm challenges various environmental turbulence, such as technological turbulence and market turbulence [21]. Both technological turbulence and market turbulence are crucial dimensions of environmental turbulence [22,23]. Along with limited resources, firms need to be more adaptable to respond environmental turbulence [24,25]. Higher environmental turbulence causes reduce the innovation activity of firms $[26,27]$ since it may raise the uncertainty and the threat of innovation investment. To constantly maintain their competitiveness, firms rely on technological innovation to deal with rapidly changing environments [11].

Many studies also have shown that technological innovation could create positive impacts and improving their competitiveness and [13,16,19,28-33]. Although studies on technological innovation are in abundance, there is nevertheless inadequately empirical evidence relating to how automotive firms improve their TIC. Even though the growing studies have been carry out to investigate the effect TIC in influencing competitive advantage and firm performance, up to now little studies has been examined the moderate effect of environmental turbulence on TIC and firm performance. Therefore, there is a need to develop a comprehensive framework for analyzing the moderating roles of two sorts of environmental turbulence: technological and market, effect on firm's TIC and firm's business performance.

Drawing upon contingency theory and the resource-based view perspectives, we suggest that environmental turbulence may moderate the relationship between TIC and business performance. This issue is important but remains mostly neglected in the existing TIC literature especially study in the automotive industry. In order to manage the high competitiveness and the various challenging business factors in the automotive industry [34] for example uncertainty about climate change policies whereby firms need to play a role in reducing global $\mathrm{CO}^{2}$ emissions through technological innovation, therefore, it is important to create better strategic planning which strongly reflects an increase in firm performance and also need to reduce operation cost. The industry is also having experienced rapid technology changes [35] and is currently in the demand for technological innovation in order to improve their business performance. Automotive industry in Malaysia was chosen due high relevance of the automotive industry in the country's GDP. In fact, according to the Malaysian Automotive Association (MAA), production of motor vehicles for 2015 totaled 614,664 units comprising 563,883 units of passenger vehicles and 50,781 units of commercial vehicles. Sales of motor vehicles amounted to 666,674 units in 2015 consisting of 591,298 units of passenger vehicles and 75,376 units of commercial vehicles. 
The article begins with a review of the literature on these areas and introduces the conceptual framework and research hypotheses in this study. Then, finally makes some concluding remarks.

\section{Conceptual framework and hypothesis development}

This study supports both resource-based view and contingency theory. The resources based view explains how firms use TIC as their valuable resources to achieve the goal, while contingency theory enlightens how exogenous variable influences the impact of such resources and capabilities on firm performance.

\subsection{Resource-based view and TIC}

Based on the assumption those firms' resources are heterogeneous and not perfectly mobile, the resource-based view (RBV) emphasizes that firms' sustainable competitive advantage is mainly attributable to their valuable, unique, inimitable, and non-substitutable resources [6]. This theory becomes a fundamental competitive advantage in which firms depend on their own tangible and intangible resources as well as their capabilities to change their temporary competitive advantage into sustainable competitive advantage. Resources are stocks of tangibles and intangibles assets partly attached to the firms [36]. However, capabilities are the complex coordinated patterns of skills and knowledge that become entrenched as organizational procedures and practices and assist firms to make the best use of its resources [3].

The concept of capabilities, derived from further research in RBV, concerns the firm skills to organize resources. Although the resources include the assets, tangible and intangible, possessed by the firm [37], the capabilities are referred to the firm ability to create a set of activities through resource deployment in order to reach a desired end ([37]; [38]). Day (1994) refers to capability as "complex of bundles of skills and gathered knowledge, implemented through organizational processes that facilitate firms to manage activities and exploit of their assets". In other words, the capabilities denote the skills allowing firms to arrange resources to achieve a desired goal.

According to Ferreira, Azevedo, \& Ortiz (2011), resources are the source of the firm's capabilities, capabilities are the vital source of its competitive advantage. So as to accomplish a sustained competitive advantage, the capabilities should be valuable, unique, difficult to identify and recognize, imperfectly mobile, not easily duplicated and substitutable [6]. In this study, TIC can be considered as a subset of firm capabilities.

Applying this approach to firms, we selected the TIC which firms can exploit in order to achieve successful performance. TIC play a pivotal role to boost firm performance $[13,19,20,33,41,42]$. From the RBV perspective, TIC are: (1) valuable because it facilitates innovative culture [43] that may lead to produce several of new products or services and improve the operational processes that efficiently generate and deliver these goods and services to the customer which lead to provide superior value to the customers $[41,44]$, which in turn customers may willing to pay a higher price for their products or services, therefore the firm can gain sustainable competitive advantage ; (2) rare because in any particular industry for example in automotive industry, few firms will be willing or able to undertake innovative activities [45] because product introduction into the market usually needs longer time, money and managerial activities costs [46,47]; and (3) imperfectly imitable because firm innovation cultures are socially complex [7]. Thus, TIC are a strategic resource and whose exploitation may provide a firm with a competitive advantage and superior performance $[20,41,45,48,49]$. 
Previous studies have conceptualized TIC with different approaches that results into various sets of capabilities to assessing a firm's TICs. Yam et al., (2011) has summarized three approaches which are asset approach, process approach and functional approach. According to [32] functional approach easier to understand, and it facilitates the multiinformants approach for the survey. However, the asset and process approaches are rather more complex to understand [13]. Table 1 presents a set of approaches and their elements TICs.

Table 1. Different approach and elements in assessing TICs (adapted from Yam et al. 2011).

\begin{tabular}{|c|c|}
\hline $\begin{array}{c}\text { Conceptual } \\
\text { Approach for TICs }\end{array}$ & Elements of TICs \\
\hline $\begin{array}{l}\text { Asset approach - } \\
\text { Christensen (1995) } \\
{[50]}\end{array}$ & $\begin{array}{ll} & \text { Science research asset } \\
- & \text { Product innovation asset } \\
\text { - } & \text { Esthetics design asset }\end{array}$ \\
\hline \begin{tabular}{l}
\multicolumn{3}{l}{ Process approach } \\
Burgelman et al. \\
$(2004,2009)$ \\
{$[43]$}
\end{tabular} & $\begin{array}{l}\text { Capabilities of a firm in } \\
\text { - Resources availability and allocation } \\
\text { - Understanding competitor innovative strategy and market } \\
\text { - Understanding technological developments relevant to firm } \\
\text { - Structural and cultural affecting internal innovative activities } \\
\text { Strategic management capability to deal with internal } \\
\text { innovative activities }\end{array}$ \\
\hline $\begin{array}{l}\text { Chiesa et al. (1996) } \\
\text { [51] }\end{array}$ & $\begin{array}{ll}\text { - } & \text { Concept generation capability } \\
\text { - } & \text { Process innovation capability } \\
\text { - } & \text { Product development capability } \\
\text { - } & \text { Technology acquisition capability } \\
\text { - } & \text { Readership capability } \\
\text { - } & \text { Capability in effective use of system and tools }\end{array}$ \\
\hline $\begin{array}{l}\text { Functional approach } \\
\text { (Yam et al. (2004) } \\
{[32]}\end{array}$ & $\begin{array}{ll} & \text { Learning capability } \\
\text { - } & \text { R\&D capability } \\
\text { - } & \text { Resources allocation capability } \\
\text { - } & \text { Marketing capability } \\
\text { - } & \text { Stranategic planning capability } \\
\end{array}$ \\
\hline $\begin{array}{l}\text { Liu \& Jiang (2016) } \\
\text { [14] }\end{array}$ & 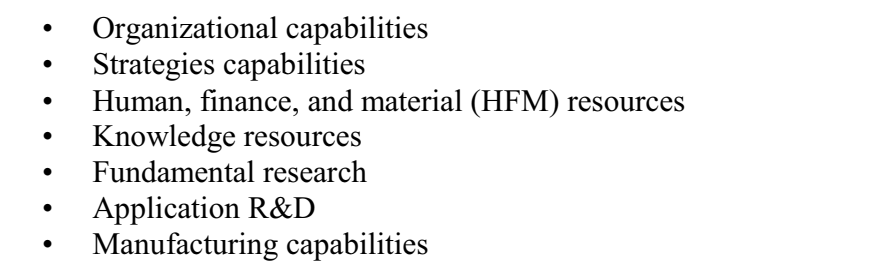 \\
\hline
\end{tabular}

In this study, we carry out the functional approach of conceptualizing TICs presented by Yam et al., (2004). According to this approach, TIC results as a complex interface of activities conducted within and between different functional departments of a firm. This approach has been used in many studies recently [13,19,28,52-54]

The framework measured TIC in seven dimensions and these dimensions are described as follows. : 
- Learning capability is the capacity to find, integrate, and develop new knowledge important for a firm's competitive success.

- R\&D capability indicates a firm's expertise to assimilate R\&D strategy, project implementation, $R \& D$ expenditure and product portfolio management.

- Resource allocation capability is the firm's ability to organize and develop its technological, financial and human resources in the innovation process.

- Manufacturing capability refers to the ability to alter R\&D results into products, which meet market needs, in line with design requirement and can also be produced in batches.

- Marketing capability refer to the capacity to advertise and sell the products on the core of aware of consumer's present and future needs, customer's access methods, and competitors' knowledge.

- Organizing capability is the capacity to establish a well-established organizational structure, cultivate an organizational culture, organize the effort of all activities concerning shared objectives, and affect the speed of innovation processes through the infrastructure it generates for developmental projects.

- Strategic planning capability is the capacity to ascertain internal strengths and weaknesses and external potentials and threats, engage in different types of strategies that can adapt to environmental changes to be superior in the highly competitive environment.

\subsection{Contingency theory}

Contingency theory was developed in the 1960s, which claimed that there was only one way that was the best way to be coordinated. Contingency theory indicated that the most effective firm strategy and structure would vary according to the environmental demand and external condition of the firm $[55,56]$. Those environmental demands and external conditions which impact the firm specific under consideration are known as contingency factors. The major contingencies identified include environment, technology, age and size [57].

Hence, contingency theory considers that firm's capability to respond business environment affects firm performance $[22,58]$. Business environment has been recognized as one of the contingency elements in strategic management research [59]. Contingency effect can be environmental turbulence, which refers to the degrees of change in the market and/or technology within an industry $[23,60]$. This concept constitutes into three factors, i.e. technology turbulence, market turbulence, and competition turbulence [23]. However, this study only focuses two categories of environmental turbulence, which is technological turbulence and market turbulence because both are the most important types of uncertainty $[21,22,61]$.

Responsiveness as crucial for firms to deal with customer needs within the technological turbulence [24]. Typically, some firms have lack of capacity to anticipate the turbulence on account of poor scanning of exact and reliable information about the industry condition [61]. Market turbulence is about the rate of dynamic composition of customers and their preferences. This causes increasing uncertainty due to changing customer's preference. Higher levels of market turbulence bring about high uncertainty due to less accurate forecast, and then firms may back off to invest in innovation activity and, as a consequence, reduce the innovation activity of firm [27]. Firm with capacity to develop their technology to respond the negative impact of marketing turbulence will be able to be better than other firms [24]. 


\subsection{Hypothesis development}

Drawing upon Resource-Based View of the firm and contingency theory, the proposed conceptual framework integrates one hierarchical component model or multidimensional constructs (TIC) that are conceptualized at second-order level and three constructs (market turbulence, technology turbulence and business performance) specified as lower-order constructs. The conceptualization of multidimensional constructs and their association with the dimensions underpinning them are derived from theory.

Our conceptual model (Fig. 1) proposes that the TIC as resources enable the firm's to enhance its business performance. Technological turbulence and market turbulence moderates the TIC- business performance relationship.

\subsubsection{Relationship between TIC and business performances}

TIC were viewed as a comprehensive set of elements of a firm that facilities and supports its technological innovative strategies [43] in the business environment and successful exploit of these capabilities to sustain competitiveness performance for the firm. TIC are a kind of integration of special assets or resources of the firm which comprises various assets such as technology, product, process, knowledge, experience [28,31,62,63]. TIC has become an important strategic resource that enables firms to construct performance in a dynamic environment, especially in high-tech industries such as the automotive industry, which is facing a rapidly changing environment $[26,64,65]$.

In the theory of resource-based view, when firms have successfully created differentiating resource configurations, they could better satisfy their customers' needs, they produced more efficiently, and in the long run, they achieved competitive advantage leading to higher performance $[6,66]$. Superior TIC and competence can improve product and/or process innovation and accelerate the pace of new product developments in the turbulent market competition, which in turn raises a firm's competitive advantage and achieving better performance over their competitors [20,31,33]. Firms are able to increase performance when they develop new ideas, create new products or services, seek new ways of doing things and be creative in their operations [32].

This study follows an audit framework proposed by Lau, Yam, \& Tang (2010) which firstly developed by Yam et al. (2004) to investigate the TIC and their impact on business performance in automotive industry. Through accumulation of TIC, firms can renovate their abilities to fit, integrate, and reorganize the internal and external resources to be better than their competitors, thereby have better performance in the changing environment. Consequently, the hypothesis is as follows:

Hypothesis $1\left(\mathrm{H}_{1}\right)$ : Firms with superior TIC have a better performance.

\subsubsection{The technological turbulence as moderating factor of TIC and business performance relationship}

Environmental turbulence is considered to come with the moderating effect that changes the direction of a relationship between TIC and firm performance. This study specifies environmental turbulence into technological turbulence and market turbulence. In this study, technological turbulence refers to the rate of technological change in an industry [23]. That technological turbulence provides a moderating effect on the relationship between TIC with business performances.

Technological turbulence may moderate the strength of the relationship between TIC and business performance. When the level of technological turbulence is high, a firm can 
adapt by utilizing its TIC [22]. Rapid changes in technology quickly make current technology obsolete. In such a situation, firms must continually develop new technology [21] and achieve competence in the latest technologies and, thereby successfully generating product and process innovations [24]. Thus, in a highly technologically turbulent environment, firms need to depend on their TIC to exploit new technology opportunities, hence improving business performance.

Based on the aforementioned arguments, we expect that the effect of TIC on business performance will increase as technological turbulence increases than when technological turbulence is low. Therefore, we hypothesize the following:

Hypothesis $2\left(\mathrm{H}_{2}\right)$ : Technological turbulence moderates the relationship between TIC and business performance.

\subsubsection{The market turbulence as moderating factor of TIC and business performance relationship}

Market turbulence indicates to the degree of change in customer preferences in an industry $[21,23]$. A turbulent market environment is described by constant changes in product preferences and customer demand [25], by a wide range of customer demands and needs, and by customer seeking for new products frequently [67].

Market turbulence may also influence the strength of the relationship between TIC and business performance. In a highly turbulent market, firms with greater TIC can achieve better performance. When market turbulence is increasing, firms likely require restructuring of their TIC to satisfy evolving needs of customer [24]. However, those operating in low market turbulence are less likely to require such adjustments. High market turbulence with fast changing customer needs prompts firms to learn about the changes; they also need to regularly identify reconfigurations of their resources and capabilities such as TIC [25] to address market changes in new ways and can exploit rapidly changing market demand[60]. Thus, in a highly turbulent market, firms with superior TIC can achieve better performance.

Based on the aforementioned arguments, we propose market turbulence will moderate the TICs and business performance relationship. Therefore, we hypothesize the following:

Hypothesis $3\left(\mathrm{H}_{3}\right)$ : Market turbulence moderates the relationship between TIC and business performance.

The conceptual model is described in the Figure 1 as follows:

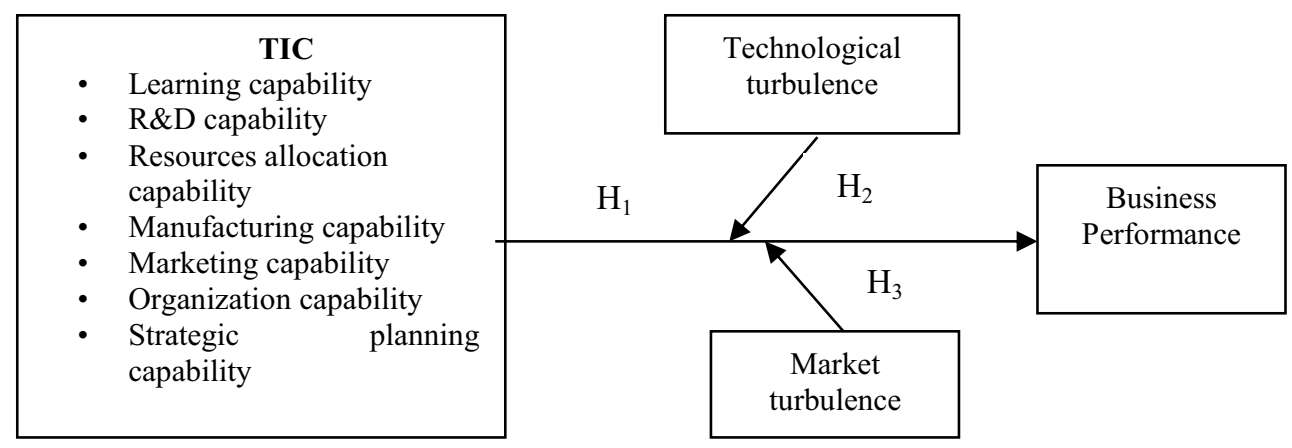

Fig. 1. Research model. 


\section{Conclusions}

Many studies have been performed to identify the relationship of TIC and business performance. Based on previous study, this study focus on TIC which is consists of learning capability, R\&D capability, resources allocation capability, manufacturing capability, marketing capability, organization capability and strategic planning capability. However, there is lack of earlier study to investigate the relationships between TIC, business performance and the moderating effects of environment turbulence on these relationships, especially in the automotive industry. A conceptual model has been recommended to study these relationships.

Our model has implications for both researchers and practitioners. For researchers, the model suggests the types of the variables that need to be included in future empirical tests of the relationship between TIC and business performance especially in automotive industry. Consequently, the model extends understanding of the moderating influence of external environment such as technological turbulence and market turbulence on the relationship between TIC and business performance.

Practitioners, on the other hand, could use the model to refine their thinking about TIC and their firm's strategic resources. The main contribution of this paper was to encourage managers to take a consideration on the relationship regarding TIC, business performance and environmental turbulence.

Based on recommended model and an earlier studied, research hypotheses are established. The next step of this study is to design a questionnaire, which will be applied for pilot study data collection in Malaysia automotive industry. We will try to conduct tests using the approaches of RBV. Therefore, the researchers as well as practitioners will have more empirical evidences associated to the fundamental theory behind the RBV, accordingly improving understanding of the relationships among TIC, and business performance and the moderating effects of environment turbulence.

\section{References}

1. N. Amira, M. Ali, M. Hanif, A. Gafar, J. Akbar, Enhancing Promotional Strategies within Automotive Companies in Malaysia. Procedia Econ. Financ. 7, 158-163 (2013).

2. K. Choi, R. Narasimhan, S. W. Kim, Opening the technological innovation black box: The case of the electronics industry in Korea. Eur. J. Oper. Res. 250, 192-203 (2016).

3. D. J. Teece, G. Pisano, A. Shuen, Dynamic Capabilities and Strategic Management. Strateg. Manag. J. 18, 509-533 (1997).

4. C. A. Bayraktar, G. Hancerliogullari, B. Cetinguc, F. Calisir, Competitive strategies, innovation, and firm performance: an empirical study in a developing economy environment. Technol. Anal. Strateg. Manag. 7325, 1-15 (2016).

5. R. M. Grant, The Resource-Based Theory of Competitive Advantage : Implications for Strategy Formulation. Calif. Manage. Rev. 114-135 (1991).

6. J. Barney, Firm Resources and Sustained Competitive Advantage. J. Manage. 17, 99120 (1991).

7. J. B. Barney \& W. S. Hesterly Strategic Management and Competitive Advantage: Concepts. (Pearson Education, Inc., publishing as Prentice Hall, (2012)).

8. C. S. Lioukas, J. J. Reuer, M. Zollo, Effects of Information Technology Capabilities on Strategic Alliances: Implications for the Resource-Based View. J. Manag. Stud. 53, 161-183 (2016).

9. R. Henderson, I. Cockburn, Measuring Competence? Exploring Firm Effects in Pharmaceutical Research. Strateg. Manag. J. 1-36 (1994).

10.F. Kong, Z. Zhang, Y. Liu, Study on the Evaluation of Technological Innovation 
Capability Under Uncertainty. 2008 4th Int. Conf. Wirel. Commun. Netw. Mob. Comput. 1-4 (2008). doi:10.1109/WiCom.2008.2999

11.Y.-L. Cheng, Y.-H. Lin, Performance Evaluation of Technological Innovation Capabilities In Uncertainty. Procedia - Soc. Behav. Sci. 40, 287-314 (2012).

12.D. J. Teece, Profiting from technological innovation: Implications for integration, collaboration, licensing and public policy. Res. Policy 15, 285-305 (1986).

13. R. C. M. Yam, W. Lo, E. P. Y. Tang, A. K. W. Lau, Analysis of sources of innovation, technological innovation capabilities, and performance: An empirical study of Hong Kong manufacturing industries. Res. Policy 40, 391-402 (2011).

14.L. Liu, Z. Jiang, Influence of technological innovation capabilities on product competitiveness. Ind. Manag. Data Syst. 116, 883-902 (2016).

15.P. Carbonell, A. I. Rodríguez-Escudero, Relationships among team's organizational context, innovation speed, and technological uncertainty: An empirical analysis. J. Eng. Technol. Manag. 26, 28-45 (2009).

16.J. C. Guan, R. C. M. Yam, C. K. Mok, N. A Ma, Study of the relationship between competitiveness and technological innovation capability based on DEA models. Eur. J. Oper. Res. 170, 971-986 (2006).

17.J. Prašnikar, M. Lisjak, A. R. Buhovac, Štembergar, M. Identifying and Exploiting the Inter relationships between Technological and Marketing Capabilities. Long Range Plann. 41, 530-554 (2008).

18. A. J. Verdu, I. Tamayo, A. Ruiz-Moreno, The moderating effect of environmental uncertainty on the relationship between real options and technological innovation in high-tech firms. Technovation 32, 579-590 (2012).

19. M. Lang, S. Hsiang, T. Nguyen, T. Vy, Mediate effect of technology innovation capabilities investment capability and firm performance in Vietnam. Procedia - Soc. Behav. Sci. 40, 817-829 (2012).

20. J. Shan, D. R. Jolly, Technological innovation capabilities, product strategy, and firm performance: The electronics industry in China. Can. J. Adm. Sci. / Rev. Can. des Sci. l'Administration 30, 159-172 (2013).

21.K.-P. Hung, Chou, C. The impact of open innovation on firm performance: The moderating effects of internal R\&D and environmental turbulence. Technovation 33, 368-380 (2013).

22.Z. Su, J. Peng, H. Shen, T. Xiao, Technological capability, marketing capability, and firm performance in turbulent conditions. Manag. Organ. Rev. 9, 115-137 (2013).

23. B. J. Jaworski, A. K. Kohli, Market Orientation: Antecedents and Consequences. J. Mark. 57, 53-70 (1993).

24.K. H. Tsai, S. Y. Yang, The contingent value of firm innovativeness for business performance under environmental turbulence. Int. Entrep. Manag. J. 10, 343-366 (2014).

25.R. Wilden, S. P. Gudergan, The impact of dynamic capabilities on operational marketing and technological capabilities: investigating the role of environmental turbulence. J. Acad. Mark. Sci. 1-19 (2014). doi:10.1007/s11747-014-0380-y

26.H. Ting, H. Wang, D. Wang, The moderating role of environmental dynamism on the influence of innovation strategy and firm performance. Int. J. Innov. Manag. Technol. 3, $13-16$ (2012).

27.D. Jiménez-Jiménez, R. Sanz-Valle, Innovation, organizational learning, and performance. J. Bus. Res. 64, 408-417 (2011).

28. G. Karagouni, I. Papadopoulos, The Impact of Technological Innovation Capabilities on the Competitiveness of a Mature Industry. Manag. Int. Bus. Econ. Syst. 1, 17-34 (2007).

29. M. Lahovnik, L. Breznik, Innovation Management and Technological Capabilities as A Source of Competitive Advantage. in Knowledge Management \& Innovation 
International Conference 2013 19-21 June 2013 771-779 ((2013)).

30. Y. Liang, D. Liu, L. Zhang, Y. Zhang, Impact of Technological Innovation Capability on Business Growth: An Empirical Study for Small and Medium-Sized Enterprises. 2010 Int. Conf. E-bus. E-Government 1177-1180 (2010). doi:10.1109/ICEE.2010.302

31. R. C. M. Yam, W. Lo, E. P. Y. Tang, K. W. Lau, Technological Innovation Capabilities and Firm Performance. World Acad. Sci. Eng. Technol. 42, 1009-1017 (2010).

32.R. C. M. Yam, J. C. Guan, K. F. Pun, E. P. Y. Tang, An audit of technological innovation capabilities in chinese firms: some empirical findings in Beijing, China. Res. Policy 33, 1123-1140 (2004).

33. C. Camisón, A. Villar-López, Organizational innovation as an enabler of technological innovation capabilities and firm performance. J. Bus. Res. 67, 2891-2902 (2014).

34.M. C. De Stefano, M. J. Montes-sancho, T. Busch, A natural resource-based view of climate change: Innovation challenges in the automobile industry. J. Clean. Prod. (2016). doi:10.1016/j.jclepro.2016.08.023

35.J. Oh, S.-K. Rhee, The influence of supplier capabilities and technology uncertainty on manufacturer-supplier collaboration: A study of the Korean automotive industry. Int. J. Oper. Prod. Manag. 28, 490-517 (2008).

36. B. A Wernerfelt, Resource-based View of the Firm. Strateg. Manag. J. 5, 171-180 (1984).

37.R. Amit, P. J. H. Schoemaker, Strategic Assets and Organizational Rent. Strateg. Manag. J. 14, 33-46 (1993).

38.C. E. Helfat, M. A. Peteraf, The dynamic resource-based view : capability lifecycles. Stategic Manag. J. 24, 997-1010 (2003).

39. G. S. Day, The Capabilities of Market-Drive Organizations. J. Mark. 58, 37-52 (1994).

40. J. J. Ferreira, S. G. Azevedo, rubén F. Ortiz, Contribution of resource-based view and entrepreneurial orientation on small firm growth. Cuad. Gest. 11, 95-116 (2011).

41. V. M. U. Azubuike, Technological Innovation Capability and Firm's Performance in New Product Development. Commun. IIMA 13, 43-56 (2013).

42.J. Shan, D. R. Jolly, Accumulation of technological innovation capability and competitive performance: a quantitative study in chinese electronic information industry. Int. J. Innov. Technol. Manag. 9, 1-18 (2012).

43. R. A. Burgelman, C. M. Christensen, S. C. Wheelwright, Strategic Management of Technology and Innovation. (McGraw-Hill/Irwin, (2009)).

44.R. I. Sabir, R. M. Sabir, Managing technological innovation: China's strategy and challenges. J. Technol. Manag. China 5, 213-226 (2010).

45.S. L. Newbert, Value. Rareness, Competitive Advantage and Performance: A Conceptual - Level Empirical Investigation of the Resource-Based View of the Firm. Strateg. Manag. J. 768, 745-768 (2008).

46.L. Radu, Investments in Technological Innovations: a Literature Review of Organization Determinants. Eur. Sci. J. 1, 52-59 (2015).

47. V. Zemlickienè, Analysis of High-Technology Product Development. Intellect. Econ. 5, 283-297 (2011).

48. J. B. Barney, Strategic Factor Markets: Expectations, Luck and Business Strategy. Manage. Sci. 32, 1231-1241 (1986).

49.S. L. Newbert, Empirical Research on Resource-Based View of the Firm: An Assessment and Suggestions for Future Research. Strateg. Manag. J. 146, 121-146 (2007).

50. J. F. Christensen, Asset profiles for technological innovation. Res. Policy 24, 727-745 (1995).

51. V. Chiesa, P. Coughlan, C. A. Voss, Development of a Technical Innovation Audit. J. Prod. Innov. Manag. 13, 105-136 (1996). 
52. A. K. W. Lau, R. C. M. Yam, E. P. Y. Tang, The impact of technological innovation capabilities on innovation performance An empirical study in Hong Kong. J. Sci. Technol. Policy China 1, 163-186 (2010).

53. A. K. W. Lau, E. Baark, W. L. W. Lo, The effects of innovation sources and capabilities on product competitiveness in Hong Kong and the Pearl River Delta. Asian J. Technol. Innov. 21, 220-236 (2013).

54.M. M. Yusr, S. S. M. Mokhtar, A. R. Othman, The effect of TQM practices on technological innovation capabilities: Applying on Malaysian manufacturing sector. Int. J. Qual. Res. 8, 197-216 (2014).

55.D. Howell, C. Windahl, R. Seidel, A project contingency framework based on uncertainty and its consequences. Int. J. Proj. Manag. 28, 256-264 (2010).

56. E. Fredericks, Infusing flexibility into business-to-business firms : A contingency theory and resource-based view perspective and practical implications B. Ind. Mark. Manag. 34, 555-565 (2005).

57. S. C. Betts, Contingency Theory: Science Or Technology? J. Bus. Econ. Res. 1, 123130 (2003).

58.G. Wang, W. Dou, W. Zhu, N. Zhou, The effects of firm capabilities on external collaboration and performance: The moderating role of market turbulence. J. Bus. Res. 1-9 (2015). doi:10.1016/j.jbusres.2015.01.002

59. D. I. Prajogo, The strategic fit between innovation strategies and business environment in delivering business performance. Intern. J. Prod. Econ. 171, 241-249 (2016).

60.K. Tsai, S. Yang, Firm innovativeness and business performance : The joint moderating effects of market turbulence and competition. Ind. Mark. Manag. 42, 1279-1294 (2013).

61.C. Terawatanavong, G. J. Whitwell, R. E. Widing, A. O. Cass, Technological turbulence , supplier market orientation, and buyer satisfaction. J. Bus. Res. 64, 911-918 (2011).

62.J. Guan, N. Ma, Innovative capability and export performance of Chinese firms. Technovation 23, 737-747 (2003).

63.M. V. Türker, A model proposal oriented to measure technological innovation capabilities of business firms - a research on automotive industry. Procedia - Soc. Behav. Sci. 41, 147-159 (2012).

64. W. Wu, D. Liang, B. Yu, Y. Yang, Strategic planning for management of technology of China' s high technology enterprises. J. Technol. Manag. China 5, 6-25 (2010).

65.K. Liao, X. Deng, E. Marsillac, Factors that influence Chinese automotive suppliers ' mass customization capabilities. Intern. J. Prod. Econ. 146, 25-36 (2013).

66. A. I. Ismail, R. C. Rose, J. Uli, H. Abdullah, The Relationship Between Organisational Resources, Capabilities, Systems and Competitive Advantage. Asian Acad. Manag. J. 17, 151-173 (2012).

67.L. Santos-vijande, A, L. I. Santos-vijande, Innovativeness and organizational innovation in total quality oriented firms : The moderating role of market turbulence. 27, 514-532 (2007). 